\title{
FORMAÇÃO INICIAL NA EDUCAÇÃO INFANTIL: um estudo bibliográfico sobre as práticas dos professores
}

\author{
Natasha Yukari Schiavinato Nakata \\ Marta Regina Furlan de Oliveira \\ Jaqueline Delgado Paschoal
}

\section{Resumo}

Partimos do pressuposto de que o professor precisa promover um ensino pautado em ações educativas à luz do desenvolvimento integral da criança. Entretanto, quando pensamos sobre o trabalho pedagógico dos professores que atuam na educação infantil, percebemos que há a existência de uma ambiguidade entre as ações que envolvem atividades de cuidados e educação. Nessa perspectiva, a problemática que guiou essa pesquisa foi: como atualmente está posta a formação dos professores que atuam na educação infantil, se considerarmos a forma como ela foi constituída? Buscando responder tal questionamento, esse artigo tem como objetivo principal refletir sobre a prática dos professores a partir da formação inicial na educação infantil. Para esta reflexão, optamos pela pesquisa de cunho bibliográfico à luz dos fundamentos da Teoria Crítica da Sociedade, pautando-nos, principalmente, em Adorno (2001, 2003, 2010) e em autores como Cerisara (2002), Paschoal e Brandão (2015), Peroza e Martins (2016). A educação por si só não é um fator potencial da emancipação, contudo, ainda assim acreditamos na sua ascendência e, por este motivo, enfatizamos sobre a importância destes profissionais compreenderem o papel educativo que exercem e representam nas instituições formativas de ensino, mais especificamente, na educação infantil.

Palavras-chave: educação; formação de professores; educação infantil.

\section{INITIAL TRAINING IN CHILD EDUCATION:}

\author{
a bibliographic study on teachers' practices
}

\begin{abstract}
We assume that the teacher needs to promote teaching based on educational actions in the light of the child's integral development. However, when we think about the pedagogical work of teachers who work in early childhood education, we realize that there is an ambiguity between the actions that involve care and education activities. In this perspective, the problem that guided this research was: how is the training of teachers working in early childhood education nowadays, if we consider the way it was constituted? Seeking to answer such a question, this article has as main objective to reflect on the practice of teachers from the initial training in early childhood education. For this reflection, we opted for bibliographic research in the light of the foundations of the Critical Theory of Society, based mainly on Adorno (2001, 2003, 2010) and on authors such as Cerisara (2002), Paschoal and Brandão (2015), Peroza and Martins (2016). Education alone is not a potential factor for emancipation, however, we still believe in their ancestry and, for this reason, we emphasize on the importance of these professionals to understand the educational role that they exercise and represent in educational training institutions, more specifically, in early childhood education.
\end{abstract}

Keywords: education; teacher training; child education. 
DOI: $10.12957 /$ teias. $\%$ Y.50945

\title{
FORMACIÓN INICIAL EN EDUCACIÓN INFANTIL: un estudio bibliográfico sobre las prácticas docentes
}

\begin{abstract}
Resumen
Asumimos que el maestro necesita promover la enseñanza basada en acciones educativas a la luz del desarrollo integral del niño. Sin embargo, cuando pensamos en el trabajo pedagógico de los maestros que trabajan en educación infantil, nos damos cuenta de que existe una ambigüedad entre las acciones que involucran actividades de cuidado y educación. En esta perspectiva, el problema que guió esta investigación fue: ¿cómo es la formación de los docentes que trabajan en educación infantil hoy en día, considerando la forma en que se constituyó? Tratando de responder a esa pregunta, este artículo tiene como objetivo principal reflexionar sobre la práctica de los docentes desde la formación inicial en educación infantil. Para esta reflexión, optamos por la investigación bibliográfica a la luz de los fundamentos de la Teoría Crítica de la Sociedad, basada principalmente en Adorno (2001, 2003, 2010) y en autores como Cerisara (2002), Paschoal y Brandão (2015) , Peroza y Martins (2016). La educación por sí sola no es un factor potencial para la emancipación, sin embargo, todavía creemos en su ascendencia y, por esta razón, enfatizamos la importancia de estos profesionales para comprender el papel educativo que ejercen y representan en las instituciones de capacitación educativa, más específicamente, en educación infantil.
\end{abstract}

Palabras clave: educación; formación de profesores; educación infantil.

\section{INTRODUÇÃO}

Do ponto de vista legal, a educação infantil é parte integrante da educação básica, situandose no mesmo patamar que o ensino fundamental e o ensino médio. Desse modo, a formação integral da criança, conforme apresentada na Lei de Diretrizes e Bases da Educação Nacional (LDB 9.394/96), inicia-se na educação infantil, e será este primeiro contato com a escola que dará base para as demais etapas de sua vida educacional. Sendo assim, este espaço formativo voltado a educação da infância deve possibilitar novos saberes e conhecimentos potencializadores de aprendizagens, de forma que contribua para sua formação humana à luz das várias linguagens do conhecimento e das experiências.

Entende-se, portanto, que é responsabilidade do professor promover um ensino intencional, pautado em ações educativas que visam promover o desenvolvimento integral dessa criança, ampliando seu universo de conhecimentos e saberes, para além do cognitivo, ou seja, que outras linguagens sejam estabelecidas nesse entorno (social, afetiva, psíquica, física, psicomotora, entre outras). Entretanto, quando refletimos sobre o trabalho pedagógico de professores da educação infantil no cenário atual em sintonia com referenciais teóricos críticos, entendemos que estão calcadas em ações formativas que intenta exclusivamente em atender as demandas do capital calcado em produtividade, padronização e reprodução de fórmulas e receituários educacionais.

Nessa perspectiva, a problemática que guiou essa pesquisa foi: como atualmente está posta a formação dos professores que atuam na educação infantil, se considerarmos a forma como ela foi constituída? Buscando responder tal questionamento, o objetivo principal desse texto é refletir sobre a prática dos professores a partir da formação inicial na educação infantil. De forma particular, objetiva-se compreender sobre a constituição da educação infantil no Brasil e refletir sobre a constituição histórica da profissão do professor que atua na Educação infantil.

Para esta reflexão, optamos pela pesquisa de cunho bibliográfico à luz dos fundamentos da Teoria Crítica da Sociedade, pautando-nos, principalmente, em Adorno (2001, 2003, 2010) e em autores como Cerisara (2002), Paschoal e Brandão (2015), Peroza e Martins (2016). Pensando na 
organização didática do texto, no primeiro momento faremos um breve histórico da constituição da Educação infantil no Brasil, buscando expor o momento no qual a criança tornou-se um indivíduo de direitos. No segundo momento, faremos um pequeno resgate histórico sobre a profissão professor, almejando nos debruçar frente à qualidade da formação que está sendo disseminada para estes profissionais.

Assim como Adorno, compreendemos, que a educação não é um fator potencial da emancipação. Contudo, acreditamos que existem possibilidades de amenizar os efeitos nocivos difundidos pela indústria cultural e pela semiformação. Por este motivo, é importante que os professores sejam conscientes do seu papel educativo, de forma que não aceitem os desmandos do capital e incentivem o pensamento crítico das crianças desde a mais tenra idade.

\section{EDUCAÇÃO INFANTIL: AVANÇOS E RETROCESSOS DA LEGISLAÇÃO NO BRASIL}

$\mathrm{O}$ atendimento às crianças no Brasil passou por importantes mudanças que foram marcadas, não apenas pelos movimentos sociais e pelas reivindicações de creches e pré-escolas, mas principalmente pela promulgação da Constituição Federal de 1988 que, em seu artigo 208, inciso IV, determinou que o dever do Estado com a educação seria efetivado mediante a garantia de educação infantil, em creche e pré-escola, às crianças até 5 (cinco) anos de idade (Redação dada pela Emenda Constitucional n. 53, de 2006).

Do ponto de vista legal, a partir da promulgação da Constituição de 1988, conforme determina o artigo 227, todas as crianças passaram a ser consideradas cidadãs de direitos:

É dever da família, da sociedade e do Estado assegurar à criança, ao adolescente e ao jovem, com absoluta prioridade, o direito à vida, à saúde, à alimentação, à educação, ao lazer, à profissionalização, à cultura, à dignidade, ao respeito, à liberdade e à convivência familiar e comunitária, além de colocá-los a salvo de toda forma de negligência, discriminação, exploração, violência, crueldade e opressão (BRASIL, 1988, Redação dada pela Emenda Constitucional n.65, de 2010).

Comungando com esses importantes eventos, a Conferência Mundial sobre os Direitos Humanos promoveu, em 1989, a Convenção das Nações Unidas sobre os Direitos da Criança, documento no qual evidenciava a educação como um dos direitos mais importantes dos cidadãos em idade escolar. Este documento destacava que os Estados deveriam reconhecer à educação como um direito da criança, a fim de que ela pudesse exercer, em igualdade de condições, esse direito.

Concomitantemente, em 13 de julho de 1990, por meio da promulgação da Lei n.8.069, mais conhecida como o Estatuto da Criança e do Adolescente, ficou estabelecido em seu artigo 54, inciso IV, que "é dever do Estado assegurar [...] o atendimento em creche e pré-escola às crianças de zero a seis anos de idade" (Redação dada pela Lei n.13.306, de 2016).

Alinhada a tais referenciais, em 20 de dezembro de 1996, a Lei 9.394 de Diretrizes e Bases da Educação Nacional (LDBEN), instituiu a Educação infantil como a primeira etapa da Educação Básica e afirmou que ela deveria ter como finalidade o desenvolvimento integral da criança até 5 (cinco) anos de idade, em seus aspectos físicos, psicológicos, intelectuais e sociais (BRASIL, 1996). Vale ressaltar que o papel dos movimentos sociais e estudiosos da área da Educação ao longo desse processo também foram de grande relevância para essa conquista. Desse modo, devido a essas 
exigências, passou a ser necessário a oferta de creches para as crianças de até três anos e pré-escolas para as crianças de quatro a cinco anos de idade.

Devemos reconhecer que a inclusão da educação infantil como primeira etapa da educação básica trouxe grandes avanços para a educação, pois rompeu com a visão assistencialista que era propagada no atendimento educativo das creches. No entanto, esse processo se deu de forma tensa e complexa perpassando por diversas disputas, uma delas era que os recursos destinados para a Educação infantil eram escassos, afinal, o Fundo de Manutenção e Desenvolvimento do Ensino Fundamental e de Valorização do Magistério - FUNDEF, criado em 1998 sob influência do Banco Mundial, determinou que a educação infantil era de responsabilidade da esfera municipal, enquanto o fundo contribuiria apenas com o ensino fundamental.

Em 1998 foi publicado o Referencial Curricular Nacional para a educação infantil - RCNEI como uma sugestão de propostas curriculares para escolas e Centros de Educação infantil. Esses referenciais eram compostos por três volumes que serviam como um guia educacional, contendo objetivos, conteúdos e orientações didáticas que levariam a criança a seu desenvolvimento integral e à formação da cidadania. Eram organizados por idade, ou seja, de zero a três anos e de três a seis anos. Conforme aponta Mello e Sudbrack (2019, p. 5), tratavam-se de manuais indispensáveis "na medida em que os professores não necessitavam ter uma formação fundamentada e alicerçada em grandes referenciais teóricos históricos, filosóficos e sociológicos".

A Resolução n.1/99 foi a primeira a instituir as DCNEI. Posteriormente e ainda em vigência temos a Resolução n.5/09, a qual comporta definições de Educação infantil, criança, currículo e proposta pedagógica, havendo um detalhamento maior da concepção de Educação infantil e da Proposta Pedagógica. Contempla ainda os princípios (éticos, político e estéticos), os quais devem ser respeitados pelas propostas pedagógicas. Nas DCNEI há referência sobre a avaliação e a articulação com o Ensino Fundamental, assim como o seu processo de concepção e elaboração (MELLO; SUDBRACK, 2019, p. 9).

Em 1999, o MEC e o Conselho Nacional de Educação (CNE) homologaram as Diretrizes Curriculares Nacionais da Educação infantil - DCNEI, evidenciando assim uma certa preocupação com a qualidade do atendimento às crianças de zero a cinco anos de idade. Essas DCNEI tinham como objetivo orientar e normatizar o currículo escolar em suas diferentes etapas, sendo atualizadas em 2009, no qual indicavam que as crianças que completassem seis anos de idade após 31 de março deveriam ter suas matrículas asseguradas na primeira etapa da educação básica, possuindo, dessa forma, o direito de frequentar a pré-escola (BRASIL, 2010).

Somente após a Resolução CEB n.5, de 17 de dezembro de 2009, que as Diretrizes Curriculares Nacionais da Educação infantil foram publicadas e distribuídas, em 2010, nas redes de ensino e instituições educativas, em material impresso numa versão mais didática diferente da resolução.

De acordo com esse documento (DCNEI) a proposta pedagógica das instituições de Educação infantil deve garantir que elas cumpram sua função sociopolítica e pedagógica:

Oferecendo condições e recursos para que as crianças usufruam seus direitos civis, humanos e sociais; assumindo a responsabilidade de compartilhar e complementar a educação e cuidado das crianças com as famílias; possibilitando tanto a convivência entre crianças e entre adultos e crianças quanto à ampliação de saberes e conhecimentos de diferentes naturezas; promovendo a igualdade de oportunidades educacionais entre as crianças de diferentes classes sociais no que 
DOI: $10.12957 /$ teias. $\%$ Y.50945

se refere ao acesso a bens culturais e às possibilidades de vivência da infância; construindo novas formas de sociabilidade e de subjetividade comprometidas com a ludicidade, a democracia, a sustentabilidade do planeta e com o rompimento de relações de dominação etária, socioeconômica, étnico-racial, de gênero, regional, linguística e religiosa (BRASIL, 2010).

Em 2006, com o objetivo de garantir um trabalho pedagógico de qualidade nas instituições de Educação infantil, o MEC apresentou a "Política Nacional de Educação infantil: pelo direito da criança de 0 a 6 anos à educação". Esse documento tinha como objetivo expandir a oferta de vagas, fortalecer as instâncias competentes e garantir a melhoria da qualidade do atendimento das crianças nas instituições de Educação infantil.

De modo a atender o previsto na Política Nacional de educação infantil, o Ministério da Educação publicou, também em 2006, o documento intitulado: "Parâmetros Nacionais de Qualidade para a educação infantil"- volumes 1 e 29, com o objetivo de estabelecer parâmetros de qualidade locais, com base nos padrões de referência nacional para os sistemas de ensino, sobretudo no que se refere à organização e funcionamento das escolas infantis. [...] Esse documento destaca, como padrão de referência para um atendimento de qualidade, quesitos necessários para a construção de uma proposta pedagógica que respeite os direitos da criança [...]. (PASCHOAL; BRANDÃO, 2015, p. 205).

É importante ressaltar que, apesar de todos esses avanços, somente em 2007 que a Educação infantil teve maior auxílio de recursos financeiros, pois o Fundo de Manutenção e Desenvolvimento do Ensino Fundamental e de Valorização do Magistério - FUNDEF passou a incluir as creches e pré-escolas no financiamento público para a Educação. Foi a partir dessa ampliação que o FUNDEF passou a ser denominado de FUNDEB - Fundo Nacional de Desenvolvimento da Educação Básica e de Valorização do Magistério, e a educação infantil começou a ter uma atenção especial de pesquisas, estudos e dos aspectos legais, pois outras políticas públicas passaram a financiar e amparar esta demanda.

Em 04 de abril de 2013, a Lei Federal n.12.796 altera a LDBEN 9.394/96, tornando obrigatória a matrícula de crianças de quatro a cinco anos de idade em instituições de educação infantil, o que colaborou para a expansão do atendimento do número de crianças dentro desses espaços educacionais. Esta mesma lei, no artigo 31, organiza regras relacionadas à avaliação, carga horária, atendimento, frequência e expedição de documentos para a educação infantil (BRASIL, 2013).

No ano de 2014, o Plano Nacional de Educação - PNE (2014-2024), por meio da Lei n.13.005, instituiu 20 metas com o objetivo de melhorar a qualidade da Educação Básica. A primeira meta era "[...] universalizar, até 2016, a Educação infantil na pré-escola para as crianças de 4 (quatro) a 5 (cinco) anos de idade e ampliar a oferta de Educação infantil em creches de forma a atender, no mínimo, $50 \%$ (cinquenta por cento) das crianças de até 3 (três) anos até o final da vigência deste PNE" (BRASIL, 2014). Dentre essas metas, quatro delas tratavam sobre a Base Nacional Comum Curricular - BNCC, assunto que abordaremos a seguir.

Conforme aponta Mello e Sudbrack (2019, p. 8),

Até o ano de 2017 as DCNEI eram utilizadas como referência para nortear o trabalho na Educação infantil e a partir de 2018, a proposta da BNCC vem ao encontro ao "tentar" resolver as questões da qualidade e dos problemas 
DOI: $10.12957 /$ teias. $\%$ Y.50945

educacionais, tendo o objetivo de oferecer subsídios para que todos recebam o ensino mínimo para o avanço do conhecimento base para todos.

Além dessa proposta, a Base Nacional Comum Curricular proporciona certa autonomia para as redes de ensino e para as instituições escolares (públicas e privadas), pois permite que construam seus próprios currículos de acordo com as características, realidades e necessidades dos alunos, desde que estejam de acordo com as propostas estabelecidas pela própria base. Esse documento visa padronizar (e não orientar) os conhecimentos, competências, habilidades e conteúdos que considera essenciais que os estudantes se apropriem desde a Educação infantil até o final do Ensino Médio, determinando o que e quando as escolas devem ensinar (MELLO, SUDBRACK, 2019).

A primeira versão da BNCC, foi apresentada pelo Ministério da Educação em setembro de 2015, no qual sugeria os direitos e objetivos de aprendizagem e desenvolvimento para as três etapas da educação básica. Essa versão ficou disponível para consulta pública até março de 2016, no qual recebeu cerca de mais de 12 milhões de contribuições. A segunda versão foi lançada em maio de 2016, onde recebeu críticas e sugestões de mais de 9 mil professores. A terceira versão da BNCC foi aprovada pelo Conselho Nacional de Educação por 20 votos a favor e 03 contrários. Em 15 de dezembro o documento foi enviado para o MEC, sendo homologado em 20 de dezembro de 2017 pelo ministro da Educação José Mendonça Bezerra Filho e pelo presidente da República Michel Temer.

Por meio deste breve resgate histórico da educação infantil, podemos perceber que o reconhecimento das crianças enquanto cidadãs de direito é uma conquista recente. Como vimos, o marco das mudanças e dos avanços na história da Educação deu-se a partir da Constituição Federal de 1988, momento no qual inúmeras discussões - tanto no âmbito das políticas públicas, quanto no âmbito de estudos e pesquisas - foram empreendidas.

Os debates que antecederam a Carta Constitucional também foram relevantes para a garantia da Educação enquanto um direito de todos e compromisso do Estado. Entretanto, para que isso realmente continue se efetivando, coloca-se como desafio urgente a formação dos profissionais que atuam dentro dessas instituições de ensino, assunto no qual abordaremos a seguir.

\section{ASPECTOS QUE INFLUENCIAM NA EDUCAÇÃO E NA FORMAÇÃO DE PROFESSORES DA EDUCAÇÃO INFANTIL}

A formação de professores para a educação infantil se dá partir do século XIX e com maior ênfase no século XX, simultaneamente ao processo de reconhecimento da educação infantil enquanto espaço para o desenvolvimento integral da criança de zero a cinco anos e, fundamentado em um currículo voltado à formação inicial e continuada docente. Devido a sua trajetória de lutas, necessitou instituir uma legislação que respondesse aos problemas históricos da época. No entanto, a realidade educativa da criança e da formação destes profissionais são tão complexas que ainda apresentam desafios para sua efetivação.

Conforme vimos no tópico anterior, historicamente, no Brasil, as creches e pré-escolas só foram incorporadas aos sistemas educacionais a partir da Lei de Diretrizes e Bases da Educação Nacional de 1996, o qual acabou rompendo com o atendimento assistencialista, muitas vezes precário, propagado para as classes mais empobrecidas da época. Isso porque a função de cuidar e educar passou a ser vista de forma indissociável, o que possibilitou que essa vinculação se tornasse 
uma oportunidade de garantir um atendimento de qualidade dentro destas instituições, no entanto, "[...] foi equivocadamente reconhecida e organizada a partir de modelos de escolarização e entendida como um período de preparação para o Ensino Fundamental" (PEROZA; MARTINS, 2016, p. 812).

De acordo com a LDBEN de 1996, é vedada a participação de professores leigos dentro do sistema de ensino pois, ao final de uma década, todos os professores da educação básica deveriam ter a formação em nível superior. Essa formação deveria ser realizada " [...] em cursos de licenciatura, de graduação plena em universidades e em institutos superiores de educação" (BRASIL, 1996). Foi a partir deste marco que profissionais que atuavam em creches, em sua grande maioria mulheres, passaram a ser consideradas professoras com formação na área (CERISARA, 2002). Assim, em 15 de maio de 2006, o Conselho Nacional de Educação instituiu as Diretrizes Curriculares Nacionais (DCNs) para o curso de graduação em Pedagogia, no qual estabeleceu no artigo $2^{\circ}$ que:

As Diretrizes Curriculares para o curso de Pedagogia aplicam-se à formação inicial para o exercício da docência na Educação infantil e nos anos iniciais do Ensino Fundamental, nos cursos de Ensino Médio, na modalidade Normal, e em cursos de Educação Profissional na área de serviços e apoio escolar, bem como em outras áreas nas quais sejam previstos conhecimentos pedagógicos (BRASIL, 2006).

A partir desse momento, iniciou-se uma corrida desenfreada por formação e, também, uma expansão dos Cursos Normais Superiores e de Pedagogia, além dos cursos de licenciaturas, desenvolvidos por instituições privadas. Em relação ao Curso Normal Superior, Rodrigues e Kuenzer (2007, p. 46) afirmam que:

Foi adotado especialmente por instituições não universitárias que criaram Institutos Superiores de Educação, visando qualificar o mais rapidamente possível os professores em exercício e adequá-los à exigência de formação em nível superior proposta pela nova LDBEN, o que configurava um mercado promissor. Apesar de legalmente constituído, esse curso não ganhou legitimidade na comunidade acadêmica e fora dela, a nova proposta de resolução, no Art. 11, permite a transformação dos Cursos Normais Superiores em Cursos de Pedagogia, por intermédio da elaboração e apresentação de um novo projeto pedagógico no prazo de um ano a contar da data da publicação.

Esse cenário nos leva a perceber que, durante décadas, os cursos normais, as licenciaturas e os cursos de Pedagogia se basearam em pressupostos educativos do Ensino Fundamental para embasar a formação docente, ou seja, os conhecimentos sistematizados referentes à infância não compunham os currículos dos cursos de formação de professores para o exercício da docência. Foi necessário tempo, investimento e esforços para, enfim, constituir um arcabouço teórico que impulsionasse as reformulações dos currículos dos cursos de formação de professores para a Educação infantil (PEROZA, MARTINS, 2016).

Referente a formação adquirida no curso de Pedagogia, segundo o artigo $5^{\circ}$, inciso II, das DCNs/2006, o egresso deveria estar apto a "compreender, cuidar e educar crianças de zero a cinco anos, de forma a contribuir, para o seu desenvolvimento nas dimensões, entre outras, física, psicológica, intelectual, social” (BRASIL, 2006). Nesse sentido, esses profissionais deveriam 
possuir competências suficientes para fazer uso de diferentes linguagens, de forma que promovesse a ampliação de conhecimentos e o desenvolvimento integral da criança.

Outro aspecto fundamental da educação da infância diz respeito a dimensão lúdica presente nas formas da criança lidar com a realidade, com os jogos e as brincadeiras. As Diretrizes Curriculares Nacionais para a Educação infantil (2010) propõem a interação e o brincar como eixos dessa etapa da educação, afinal, é por meio da brincadeira que ocorre a aprendizagem e a sociabilidade da criança, uma vez que, por meio dela, a criança revela seus sentimentos, suas representações sobre o mundo e sobre a realidade em que vive.

Dentre as recentes mudanças ocorridas na legislação está a homologação da Base Nacional Comum Curricular (BNCC), em 2017, que busca padronizar e alinhar a formação inicial e continuada dos educadores. Esse documento visa "contribuir para o alinhamento de outras políticas e ações, em âmbito federal, estadual e municipal, referentes à formação de professores, à avaliação, à elaboração de conteúdos educacionais e aos critérios para a oferta de infraestrutura adequada para o pleno desenvolvimento da educação".

Além disso, para assegurar as aprendizagens essenciais definidas para cada etapa da Educação Básica, a BNCC tem como papel complementar "[...] criar e disponibilizar materiais de orientação para os professores, bem como manter processos permanentes de formação docente que possibilitem contínuo aperfeiçoamento dos processos de ensino e aprendizagem" (BRASIL, 2017, grifo nosso).

A partir dessa proposta da BNCC, trazemos algumas reflexões: esse aperfeiçoamento contínuo disposto no documento realmente se efetiva, se considerarmos a formação deste final de século? É possível pensar a educação numa direção que repense o passado? Como defender uma formação cultural crítica, sem perder de vista que a cultura se construiu e fortaleceu como monumento de barbárie?

É nesse sentido que assentimos com a afirmação de Adorno (2003, p. 155), quando ele afirma que:

A tese que gostaria de discutir é a de que desbarbarizar tornou-se a questão mais urgente da educação hoje em dia. O problema que se impõe nesta medida é saber se por meio da educação pode-se transformar algo de decisivo em relação a barbárie. Entendo por barbárie algo muito simples, ou seja, que, estando na civilização do mais alto desenvolvimento tecnológico, as pessoas se encontrem atrasadas de um modo peculiarmente disforme em relação a sua própria civilização.

Portanto, se a barbárie consiste no oposto da formação, subentende-se que a escola tem a função de contribuir para a desbarbarização da humanidade, por mais "[...] limitados que sejam seu âmbito e suas possibilidades" (ADORNO, 2001, p. 176). Porém, a questão na qual devemos nos preocupar é saber em qual proporção a educação tem se transformado, ela própria, em uma teoria e prática legitimadoras desta barbárie.

A formação na qual apontamos deveria ter como consequência principal "[...] tornar os indivíduos aptos a se afirmarem como racionais numa sociedade racional, como livres numa sociedade livre" (ADORNO, 2010, p. 13). Contudo, tal determinação não se efetivou, visto que, nas palavras de Adorno (2010, p. 14), "[...] os dominantes monopolizaram a formação cultural numa sociedade formalmente vazia". Com isso, estabeleceram formalmente desigualdades, tornando-as aceitas sem resistência pela sociedade de classes. 
Essa (semi) formação ofertada às massas, legitimou uma formação genérica, superficial, que se opõe à formação autêntica, compreendida como cultura, ou seja, a formação que para Adorno (2010, p. 20-21) “[...] tem como condições a autonomia e a liberdade”. Pucci et al. (2009, p. 71) corrobora e complementa a análise afirmando que:

[...] as reformas escolares, necessárias para adequar a educação aos novos tempos, descartaram a antiga autoridade do mestre e, ao mesmo tempo, enfraqueceram ainda mais a dedicação e o aprofundamento íntimo do espiritual. [...] A sabedoria do mestre, [...] se torna demodê diante das exigências do "que fazer" formativo contemporâneo.

Nesta perspectiva, é importante salientarmos que o enfrentamento do problema da qualidade da formação dos professores que atuam na Educação infantil vai muito além de questões legais e, por este motivo, é necessário levarmos em consideração as condições históricas reais nas quais esses profissionais exercem sua profissão.

Conforme aponta Silva (2014), as condições adversas somadas ao baixo reconhecimento da profissão têm ocasionado alto grau de frustação profissional, evasão de professores e, por conseguinte, altos índices de licença do trabalho, principalmente por motivos de adoecimento. Além disso, o autor pontua que:

[...] o predomínio do tecnicismo como vertente pedagógica repercutiu no perfil do professor que atuava junto às classes populares: a este professor bastava $\mathrm{o}$ domínio de habilidades técnicas destinadas a subsidiar a reprodução do conhecimento disciplinar prescrito nos livros didáticos. Se o papel da escola era reduzido a adaptar esses trabalhadores ao mercado de trabalho, os seus professores não precisavam de formação aprofundada. Daí a desvalorização deste profissional do ponto de vista da sua formação e de seu entendimento, afinal, qualquer um servia para ser professor naquela situação (SILVA, 2014, p. 89, grifo nosso).

Compreende-se, nesse sentido, que a profissão professor encontra-se "circunscrita historicamente e sofre as determinações e os condicionamentos alienantes que lhe são próprios" (SILVA, 2014, p. 88). Desse modo, este profissional exerce sua profissão dentro de contextos prédeterminados, dos quais está sujeito a modelos e regras que ditam a forma correta de como ser professor.

Em nosso tempo, a desvalorização desse profissional da infância se manifesta devido a inúmeras medidas implementadas pelas políticas públicas e empresariais - como contenção salarial, aumento de crianças dentro das salas de aula, supervalorização dos livros didáticos, dentre outros - e, também, pela falta de reconhecimento de sua autoridade e da importância de sua profissão, a qual tem sido considerada dispensável para a sociedade globalizada. Dessa forma, estes profissionais da Educação infantil vêm sendo rebaixados a um lugar secundário no processo de ensino-aprendizagem, onde estão mostrando uma autoridade desacreditada e desvalorizada dentro das salas de aulas (PUCCI et al., 2009).

Pucci et al. (2009, p. 85) afirma ainda que,

[...] a desqualificação da educação, ao se generalizar para todos os estratos sociais, parece haver surrupiado o esforço criativo de [...] professores e de funcionários nas escolas, aniquilando, pouco a pouco, as chances da educação possibilitar uma formação voltada ao desenvolvimento do indivíduo, decompondo ou 


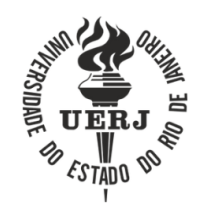

DOI: $10.12957 /$ teias.\%Y.50945

comprometendo a fruição de subjetividades criativas e críticas, minimamente desejáveis numa sociedade realmente democrática.

Por este motivo, é importante reforçarmos a necessidade de que os professores não sejam adultos semiformados, que aceitam os desmandos do capital e sucumbam ao consumismo desordenado. Afinal, Adorno (2003) entende a educação como uma exigência política democrática que, para operar conforme o seu real conceito, demanda formação de sujeitos emancipados que buscam a saída da menoridade. No entanto, para que isso ocorra, é necessário que este profissional seja capacitado a criar alternativas que busquem uma prática educativa autônoma, que ultrapasse as possibilidades que o sistema oferece e vá além do que ele impõe. Compreendemos que a educação sozinha não é detentora de todas as soluções, contudo, acreditamos que existam caminhos possíveis para amenizar os efeitos nocivos difundidos pelo sistema capitalista e pela Indústria Cultural.

\section{CONSIDERAÇÕES FINAIS}

Nessa trajetória de mais de vinte anos de promulgação da LDBEN/1996, ocorreram mudanças significativas no que se refere a formação de professores da educação infantil e, de modo geral, no reconhecimento dessas instituições enquanto parte da educação básica. Todavia, esses avanços ainda não foram suficientes para proporcionar um atendimento de qualidade dentro destas instituições, promover a valorização dos profissionais que atuam na educação da infância e propiciar práticas educativas que sejam adequadas para o desenvolvimento dessas crianças.

Afinal, uma educação que pretende ser emancipatória e crítica, não pode eximir-se de sua responsabilidade em promover uma formação cultural problematizadora, que favoreça o desenvolvimento de personalidades autocríticas e reflexivas, a qual contrapõe-se ao processo de coisificação que impera na atual sociedade administrada. Compreende-se, dessa forma, que a educação infantil deve estar pautada em uma concepção pedagógica que assegure o desenvolvimento das potencialidades da criança, por meio do acesso ao conhecimento científico, considerando as especificidades de seu desenvolvimento.

Por esse motivo, os profissionais que atuam na educação infantil devem ser indivíduos conscientes, que incentivam o pensamento crítico desde a infância, promovendo atividades educativas que habituem as crianças a expressarem suas opiniões criticamente. Assim, a profissão do educador deve estar fundamentada na efetivação de um cuidar que promova a educação e de uma educação que não deixe de cuidar, ou seja, que atenda à criança em suas necessidades e exigências essenciais desde a mais tenra idade em atividades, espaços e tempos de ludicidade.

\section{REFERÊNCIAS}

ADORNO, Theodor W. Tabus a respeito do professor. Tradução de Newton Ramos-de-Oliveira. In: ZUIN, Antônio Álvaro Soares; PUCCI, Bruno; RAMOS-DE-OLIVEIRA, Newton. Adorno: o poder educativo do pensamento crítico. 3. ed. Petrópolis: Vozes, 2001.

ADORNO, Theodor W. Educação e emancipação. São Paulo: Paz e Terra, 2003.

ADORNO, Theodor W. Teoria da Semiformação. In: PUCCI, Bruno. ZUIN, Antônio Álvaro Soares; LASTÓRIA, Luiz Antônio Calmon Nabuco (org.). Teoria Crítica e inconformismo: novas perspectivas de pesquisa. Campinas: Autores Associados, 2010. p. 7-40. 
DOI: $10.12957 /$ teias. $\%$ Y.50945

BRASIL. Constituição (1988). Constituição da República Federativa do Brasil. Brasília: Senado Federal, 1988.

BRASIL. Lei n. 8.069, de 13 de julho de 1990. Dispõe sobre o Estatuto da Criança e do Adolescente e dá outras providências. Diário Oficial da União, Brasília, 16 jul. 1990.

BRASIL. Lei n. 9.394, de 20 de dezembro de 1996. Estabelece as diretrizes e bases da educação nacional. Diário Oficial da União, Brasília, 23 dez. 1996.

BRASIL. Ministério da Educação. Secretaria de Ensino Fundamental. Referencial curricular nacional para a Educação infantil. Brasília, DF: MEC, 1998.

BRASIL. Resolução n. 01, 7 de abril de 1999. Institui as Diretrizes Curriculares Nacionais para a Educação infantil. Diário Oficial da União, Brasília, 13 abr. 1999.

BRASIL. Conselho Nacional de Educação. Resolução CNE/CP n. 1, de 15 de maio de 2006. Institui Diretrizes Curriculares Nacionais para o Curso de Graduação em Pedagogia, Licenciatura. Diário Oficial da União, Brasília, 16 mai. 2006, Seção 1, 11p.

BRASIL. Ministério da Educação. Secretaria de Educação Básica. Diretrizes curriculares nacionais para a educação infantil / Secretaria de Educação Básica. Brasília: MEC, SEB, 2010.

BRASIL. Lei n. 12.796, de 4 de abril de 2013: altera a Lei n. 9.394 de 20 de dezembro de 1996, que estabelece as diretrizes e bases da educação nacional, para dispor sobre a formação dos profissionais da educação e dar outras providências. Brasília: Planalto Central, 2013.

BRASIL. Câmara dos Deputados. Plano Nacional de Educaşão 2014-2024. Lei no 13.005, de 25 de junho de 2014. Brasília: Edições Câmara, 2014.

BRASIL. Base Nacional Comum Curricular (BNCC). Educação é a Base. Brasília: MEC/CONSED/UNDIME, 2017.

CERISARA, Ana Beatriz. O Referencial Curricular Nacional para a Educação infantil no contexto das reformas. Educaşão e Sociedade, v. 23, n. 80, p. 326-345, set. 2002.

MELLO, Ana Paula Barbieri de; SUDBRACK, Edite Maria. Caminhos da Educação infantil: da Constituição de 1988 até a BNCC. Revista Internacional de Educação Superior, Campinas, v. 5, p. 1-21, fev. 2019.

PASCHOAL, Jaqueline Delgado; BRANDÃO, Carlos da Fonseca. A contribuição da legislação para a organização do trabalho pedagógico na Educação infantil Brasileira. HISTEDBR, Campinas, n. 66, p. 196-210, dez. 2015.

PEROZA, Marilúcia Antônia de Resende; MARTINS, Pura Lúcia Oliver. A formação de professores para a Educação infantil no limiar dos vinte anos da Lei de Diretrizes e Bases da Educação Nacional 9.394/96. Revista Diálogo Educacional, Curitiba, v. 16, n. 50, p. 809-829, out./dez. 2016.

PUCCI, Bruno; ALMEIDA, Jorge de; LASTÓRIA, Luiz Antônio Calmon Nabuco (org.). Experiência formativa e emancipação. São Paulo: Nankin, 2009.

RODRIGUES, Marli de Fátima; KUENZER, Acácia Zeneida. As diretrizes curriculares para o curso de Pedagogia: uma expressão da epistemologia da prática. Revista Olhar de Professor, v. 10, n. 1, p. 35-62, 2007.

SILVA, Vandel Pinto da. Formação de professores na perspectiva da filosofia da práxis: quem educa o educador? In: MILLER, Stela; BARBOSA, Maria Valéria; MENDONÇA, Sueli Guadelupe 
DOI: $10.12957 /$ teias.\%Y.50945

de Lima (org.). Educação e Humanização: as perspectivas da teoria histórico-cultural. Jundiaí: Paco Editorial, 2014. p. 83-96.

Submetido em maio de 2020

Aprovado em outubro de 2020

\section{Informações das autoras}

Natasha Yukari Schiavinato Nakata

Universidade Estadual de Londrina

E-mail:naaschiavinato@gmail.com

ORCID: http://orcid.org/0000-0002-7455-8504

Link Lattes: http://lattes.cnpq.br/ 6416445608575007

Marta Regina Furlan de Oliveira

Universidade Estadual de Londrina

E-mail:marta.furlan@yahoo.com.br

ORCID: http://orcid.org/0000-0003-2146-2557

Link Lattes: http://lattes.cnpq.br/8423465824507075

Jaqueline Delgado Paschoal

Universidade Estadual de Londrina

E-mail: jaquelinedelgado@uol.com.br

ORCID: https://orcid.org/0000-0002-7961-2362

Link Lattes: http://lattes.cnpq.br/6771832078958203 